\title{
Aspectos da difusão de covid-19 na região geográfica imediata de Imperatriz, Maranhão, Brasil
}

\author{
Aspects of the diffusion of covid-19 in the immediate geographic region of Imperatriz, \\ Maranhão, Brazil
}

\begin{abstract}
Allison Bezerra Oliveira
Doutor em Geografia. Universidade Estadual da Região Tocantina do Maranhão Grupo de Pesquisas Socioeconômicas do Maranhão - GPS/UEMASUL, Brasil allisonbzr@gmail.com

Alberto Soares Madeira Médico oftalmologista. Instituto Allume de oftalmologia, Brasil alberto madeira@msn.com

Diego Armando de Sousa Paz Graduando em Geografia, bolsista de Apoio Técnico Institucional Universidade Estadual da Região Tocantina do Maranhão, Brasil Grupo de Pesquisas Socioeconômicas do Maranhão - GPS/UEMASUL d.armando146@hotmail.com
\end{abstract}

\begin{abstract}
Resumo
O presente trabalho tem por objetivo discutir aspectos da difusão da covid-19 na região geográfica imediata da cidade de Imperatriz, no estado do Maranhão. O período analisado compreende os 100 primeiros dias de pandemia no estado. São considerados dados da espacialização de UTIs, leitos hospitalares e respiradores/ventiladores mecânicos no estado, bem como informações sobre a evolução viral e procedência geográfica de pacientes nesse período. As principais fontes de dados são o Datasus e a Secretaria de Estado da Saúde do Maranhão. Os aspectos estudados sugerem que a concentração de equipamentos médico-hospitalares em Imperatriz, configura-se como expressivo gargalo no enfrentamento da pandemia de Sars-CoV-2, na medida em que desencadeia fluxos de pessoas de centros com menor oferta de serviços em busca de atendimento médico, resultando em amplas áreas de contágio além de distorções quanto a origem geográfica dos casos.
\end{abstract}

Palavras-chave: Região Geográfica de Imperatriz, Covid-19, Maranhão.

\begin{abstract}
The present study aims to discuss aspects of the diffusion of covid-19 in the immediate geographic region of the city of Imperatriz, in Maranhão. The period analyzed comprises the first 100 days of the pandemic in the state. Data on ICU spatialization, hospital beds and mechanical ventilators/ventilators in the state are considered, and information on viral evolution and geographic origin of patients in this period. The main data sources are Datasus and the State Department of Health of Maranhão. The aspects studied suggest that the concentration of medical-hospital equipment in Imperatriz is a significant bottleneck in the fight against pandemic the Sars-CoV-2, in that it triggers flows of people from centres with less offer of services in search of medical care, resulting in wide areas of contagion and distortions as to the geographical origin of the cases.
\end{abstract}

Keywords: Immediate Geographic region of Imperatriz, Covid-19, Maranhão. 


\section{INTRODUÇÃO}

Em 30 de janeiro de 2020, a Organização Mundial da Saúde (OMS) declarou emergência internacional de saúde pública, evidenciando o contágio em nível global pelo novo coronavírus (SarsCoV-2); no mês de março foi declarado o estado de pandemia. A cronologia do coronavírus se inicia oficialmente no dia 12 de dezembro de 2019, data em que o primeiro paciente foi internado em hospital na China, na cidade de Wuhan. A partir daí, o vírus espalhou-se rapidamente por outros países (LI et al., 2020; WHO, 2020).

Os coronavírus são vírus de RNA de cadeia positiva com o maior genoma viral entre os vírus RNA. As partículas do vírus são envolvidas em "espigas” de proteínas na superfície da membrana em uma estrutura circular no formato de coroa, daí a derivação do nome. Eles são divididos em três grupos: os vírus dos grupos I e II têm mamíferos como hospedeiros; o grupo III, as aves. Até o momento, acredita-se que apenas esses dois grupos são passíveis de contágio (VAN DER HOEK; PYRC; BERKHOUT, 2006).

O agente patógeno da covid-19 é um novo vírus corona (Sars-Cov-2), pertencente à família Coronavírus, gênero Betacoronavírus e subgênero Sarbecovírus (LI et al., 2020). A família Coronavírus pode causar diversas doenças nos seres humanos, contudo, a principal complicação está associada a doenças graves do trato respiratório, com alto índice de mortalidade em humanos (DROSTEN et al., 2003; KSIAZEK et al., 2003; OSTERHAUS; FOUCHIER; KUIKEN, 2004).

Com grande potencial de contágio, seus sintomas podem variar, assemelhando-se a um simples resfriado ou até a uma pneumonia severa, considerando ocorrências de tosse, febre, coriza, dor de garganta, além de dificuldade para respirar. Isso faz com que nos casos mais leves, a doença seja confundida com gripes comuns. A transmissão ocorre por meio de gotículas de saliva, espirro, tosse, catarro, além do contato com mãos, superfícies ou objetos contaminados. Por isso, o isolamento social vem sendo tratado desde o início como a principal estratégia sanitária de contenção (BRASIL, 2020c).

Há incertezas quanto ao comportamento do Sars-CoV-2 e seus impactos na saúde, o que torna seu acompanhamento mais complexo, levando a imprecisões na adoção de estratégias para o seu enfrentamento. Estes aspectos somados às vulnerabilidades - principalmente aquelas de ordem socioeconômica - de países periféricos como o Brasil, ampliam a exposição viral e o contágio. (BARRETO et al., 2020; FARIAS, 2020).

Até meados de dezembro de 2020, o número de casos confirmados de covid-19 ultrapassava 71 milhões de casos em todo o mundo, e mais de 1.641 .000 óbitos. O primeiro caso detectado no Brasil data de 26 de fevereiro, no estado de São Paulo: um homem de 61 anos que havia estado na Itália. A partir daí, muito rapidamente o país alcançou a segunda colocação mundial no número de 
casos detectados e de óbitos confirmados, ficando atrás apenas dos Estados Unidos (BRASIL, 2020b; JOHNS HOPKINS UNIVERSITY, 2020).

Para Haesbaert (2020), a pandemia de covid-19 e seu enfrentamento apresentam clara dimensão geográfica. Nesse ponto, destacam-se duas perspectivas evidenciadas pelo autor: a primeira trata do caráter nada democrático do vírus, que afeta de modo mais brutal os já fragilizados: idosos, enfermos e incapacitados; a segunda se refere ao enfrentamento que demanda reclusão temporária, realmente possível apenas para os poucos que dispõem de condições para o distanciamento social e isolamento. Nesse sentido, o autor pontua que há muitas "lições geográficas" a serem aprendidas a partir dos mecanismos de contenção territorial que têm se dado em função da pandemia e que deixam clara a importância da materialidade do território, mesmo num mundo tão informacional e tecnológico.

No Maranhão, o primeiro caso detectado data do dia 20 de março, na capital São Luís, em um homem que havia retornado de viagem a São Paulo; o primeiro óbito ocorreu no dia 29 do mesmo mês. O estado ocupa a $26^{\mathrm{a}}$ posição no Índice de Desenvolvimento Humano Municipal brasileiro (IDHM) e a $23^{\mathrm{a}}$ posição no Índice de Gini, que mede a desigualdade no país. Além disso, apresenta profunda concentração na oferta de serviços médico-hospitalares, o que provoca intensa mobilidade de pessoas em busca de diagnóstico e tratamento, deslocando-se dos centros menores para os maiores (ARAÚJO, 2016; PNUD; IPEA; FJP, 2013; MARANHÃO, 2020b).

Dessa forma, como destacam Bessa e Luz (2020), o deslocamento espacial da população, sobretudo entre centros urbanos, em busca de bens e serviços, e a complexa circulação que permite o provimento desses serviços provocam intercâmbios geográficos relevantes na difusão da pandemia de covid-19.

Os dados sobre a difusão da doença no país indicam que se trata de um modelo hierárquico, fortemente relacionado com as interações espaciais já existentes na rede urbana brasileira, as quais exigem complexa mobilidade espacial das pessoas, proporcionando circulação e conectividade (SPOSITO; GUIMARÃES, 2020).

Nesse contexto, considerando a ampla concentração de serviços médico-hospitalares em poucas cidades maranhenses e as mobilidades sociais motivadas pela busca de diagnóstico/tratamento para covid-19, o presente trabalho tem por objetivo discutir aspectos da difusão da covid-19 na região geográfica imediata da cidade de Imperatriz, no estado do Maranhão. O ponto central que norteia este trabalho trata da compreensão de que a enorme disparidade na oferta de serviços de saúde no Maranhão e em especial nos municípios da Região Geográfica Imediata de Imperatriz desencadeia enorme fluxos de pessoas em busca de atendimento ampliando a difusão viral e subdimensionando informações sobre a procedência geográfica do paciente, elevando assim o número de casos no centro urbano polarizador. 
Além desta introdução, metodologia da pesquisa e das considerações finais, este artigo segue a seguinte estrutura: primeiro, trata de aspectos da oferta de oferta de equipamentos médicohospitalares no Maranhão; a seguir, contextualiza o enfrentamento da covid-19 no Maranhão a partir de uma análise dos 100 primeiros dias de pandemia; por fim, discute aspectos da difusão de covid-19 na Região Geográfica Imediata de Imperatriz, Maranhão.

\section{METODOLOGIA DA PESQUISA}

Enquanto recorte espacial, a pesquisa delimita a Região Geografia Imediata de Imperatriz (Figura 1), no estado do Maranhão, composta por 17 municípios. O estado é composto por 217 municípios, que estão distribuídos em 22 regiões geográficas imediatas, que por sua vez estão agrupadas em cinco regiões geográficas intermediárias, as regiões geográficas imediatas, substituíram as microrregiões a partir da delimitação de 2017 do IBGE.

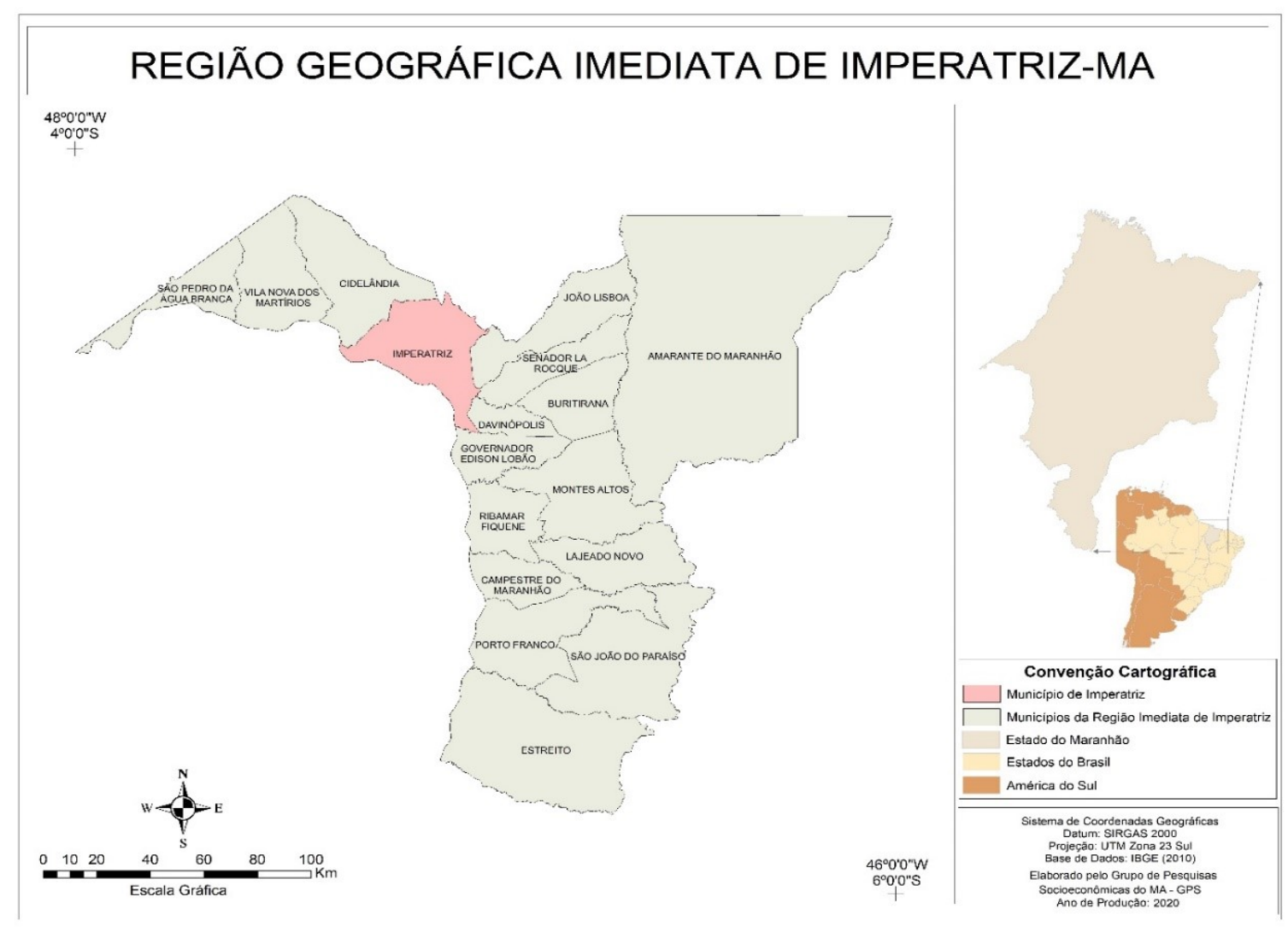

Figura 1 - Mapa da Região Geográfica Imediata de Imperatriz, Maranhão.

Fonte: Dados do IBGE (2020).

Org.: Os autores (2020)

As regiões geográficas imediatas são agrupamentos de municípios que têm como principal referência a rede urbana e possuem um centro urbano local, como base (neste caso, a cidade de Imperatriz). Esta delimitação leva em consideração conexões de cidades próximas através de relações 
de dependência e deslocamento da população em busca de bens, prestação de serviços e trabalho. As regiões intermediárias, por sua vez, são agrupamentos de regiões imediatas que são articuladas através da influência de uma metrópole, capital regional ou centro urbano representativo dentro do conjunto (IBGE, 2018).

Imperatriz dentro do quadro regional, se apresenta enquanto Capital Regional C evidenciando forte e direta polarização sobre os municípios ${ }^{1}$ de sua região geográfica imediata, sob diversos aspectos, a saúde em especial é um deles, o que induz a intensa dinâmica dos municípios vizinhos em busca de atendimento e/ou tratamento. No quadro atual, sua posição de destaque quanto a oferta de serviços médico-hospitalares, fica atrás apenas da capital do estado, São Luís. Tal particularidade justifica o recorte deste trabalho.

Já o recorte temporal compreende os 100 primeiros dias de pandemia no estado, contados a partir do primeiro caso confirmado. Tal recorte considera o período de maior intensidade de propagação viral (MARANHÃO, 2020b).

Trata-se de uma análise ${ }^{2}$ espacial mais empírica, ancorada na sistematização de dados secundários publicamente disponíveis, seguida de exame qualitativo (BESSA; LUZ, 2020). Analisase tanto a evolução da pandemia no Maranhão, quanto a distribuição de equipamentos médicohospitalares, bem como a consequente mobilidade de pessoas com covid-19, ou com suspeita da doença, em busca de atendimento na Região Geografia Imediata de Imperatriz.

Para fins de análise, foram considerados três equipamentos médico-hospitalares fundamentais no tratamento de pacientes com covid-19 - e sua distribuição no âmbito da oferta de serviços de saúde no Maranhão: a) Unidades de Terapia Intensiva (UTIs); b) ventiladores/respiradores mecânicos; e c) leitos hospitalares públicos e privados. Os dados coletados são do Departamento de Informática do Sistema Único de Saúde (Datasus), por meio do seu sistema Informações de Saúde (Tabnet).

Foram analisadas quatro variáveis do enfrentamento e da difusão viral, no Maranhão, no período delimitado: a) evolução de casos confirmados e número de óbitos; b) perfil etário de contágio e de óbitos; c) evolução de ampliação e ocupação de leitos hospitalares, clínicos e de UTI; d) distribuição espacial municipal de casos confirmados e de óbitos. Os dados foram sistematizados a partir dos boletins diários da Secretaria de Estado da Saúde do Maranhão (SES/MA) e do Datasus. Estes dados serviram para, a partir da compreensão em uma escala regional, se partir para uma escala menor, a da Região Geográfica Imediata.

\footnotetext{
${ }^{1}$ Além dos aspectos mencionados, os municípios fazem parte também da delimitação conhecida por Região Tocantina do Maranhão.

${ }^{2}$ Resultante de monitoramento de dados referentes à dinâmica espacial de covid-19 desenvolvido no Grupo de Pesquisas Socioeconômicas do Maranhão - GPS da Universidade Estadual da Região Tocantina do Maranhão - UEMASUL.
} 
A dinâmica em torno da mobilidade de pessoas em busca de atendimento e/ou tratamento na Região Geográfica Imediata foi analisada a partir das relações e funcionalidades estabelecidas pela regionalização de saúde do estado, pactuada pela Comissão Intergestores Bipartite (CIB/MA), por meio da Resolução no 44/2011, de 16 de junho de 2011. Além da procedência dos pacientes atendidos em Imperatriz, no período analisado, com quadro clínico de problemas no sistema respiratório e/ou covid-19. Os dados foram coletados na base de dados do Cartão Nacional de Saúde (CNS) e do relatório de atendimentos médicos, categoria $\mathrm{J}^{3}$, cadastrados no Datasus.

A construção de todos os mapas de pesquisa foi estruturada com base em estratégias de geoprocessamento, utilizando-se o software ArcMap 10.6. Também foram criadas tabelas, quadros e gráficos a partir de um conjunto de informações geográficas oriundas de bases de dados secundárias.

\section{ASPECTOS DA OFERTA DE OFERTA DE EQUIPAMENTOS MÉDICO- HOSPITALARES NO MARANHÃO}

O espaço urbano-regional é, em essência, contínuo e fluído, fincado sobre interações dos mais diversos tipos e escalas que se estabelecem tendo como alicerce posições geográficas complexas que garantem a inclusão dos centros urbanos por meio de redes de transportes ou de comunicação. Essas redes conectam os centros e estabelecem níveis de hierarquia e dependência entre eles (SANTOS, 1996).

Uma rede urbana pode ser compreendida como um conjunto de centros urbanos articulados através de suas funcionalidades, por onde circulam pessoas, ideias, informações e mercadorias (CORRÊA, 1997, 2006). Bessa e Luz (2020) explicam a dinâmica das redes:

[...] são firmadas em torno dos centros que exercem influências regionais, sub-regionais, microrregionais e, até mesmo, dos centros locais, cuja incapacidade de oferecer bens e serviços é, geralmente, compensada pela posição geográfica junto a essas redes e pela proximidade espacial com os centros que possuem uma mais ampla oferta de funções urbanas. (BESSA; LUZ, 2020, p. 10).

Compreender as dinâmicas das redes urbanas é salutar na medida em que permite amplificar o entendimento acerca das relações essenciais - articulação, dependência e circulação - entre as cidades e os diversos atores que delas fazem parte, sobretudo no contexto regional. Com isso, tornase mais clara a organização hierárquica dos centros urbanos a partir da polarização entre eles, que se observa, por exemplo, na capacidade de desenvolvimento e atração de pessoas e capitais ou na oferta de serviços, como os de saúde.

\footnotetext{
${ }^{3}$ No período analisado, não havia ainda clareza e rigor metodológico quanto aos dados de pacientes diagnosticados com covid-19, inseridos no Datasus, referente à procedência geográfica dos pacientes ou ao quadro clínico real. Nos dados online, muitos pacientes com covid-19 foram inseridos dentro do universo de doenças do sistema respiratório, por isso selecionou-se o "Grupo J", que trata justamente desse tipo de quadro clínico. Embora a localização geográfica dos casos seja apresentada nos boletins diários da Secretaria de Saúde, não se informa onde os casos foram detectados, exceto quando se utiliza informações do Datasus, o que se apresenta como verdadeiro desafio para análise mais profunda da mobilidade de contágio no estado.
} 
Usar a escala estadual, neste primeiro momento, permite a possibilidade de vislumbrar de forma mais ampla, os diversos gargalos municipais existentes no estado e disparidades que impactam diretamente a atuação dos centros mais relevantes e suas Regiões Geográficas de Influência.

Desta forma, a oferta de serviços médico-hospitalares move os fluxos de pessoas que, normalmente, deslocam-se de centros menores para os maiores em busca de serviços de urgência e de média e alta complexidade, contribuindo para a constituição das hierarquias das cidades dentro do espaço regional. Neste caso, a cadeia produtiva da saúde deve ser considerada como um atributo socioeconômico intrínseco à expansão da vida urbana, que amplia a importância da dinâmica cidaderegião na medida em que atrai pessoas de diversos lugares. A atração de pessoas para esses centros faz com que se constitua uma continuidade espacial, formada por hierarquias e nós, de uma extensa rede urbana que estimula a pendularidade de grupos sociais em busca de diversos serviços.

A figura 2, a seguir, evidencia a distribuição espacial de Unidades de Terapia Intensiva (UTIs), estrutura hospitalar caracterizada como unidade complexa, dotada de sistema de monitoramento contínuo, que admite pacientes potencialmente graves ou com possibilidade de recuperação mediante suporte e tratamento intensivos.
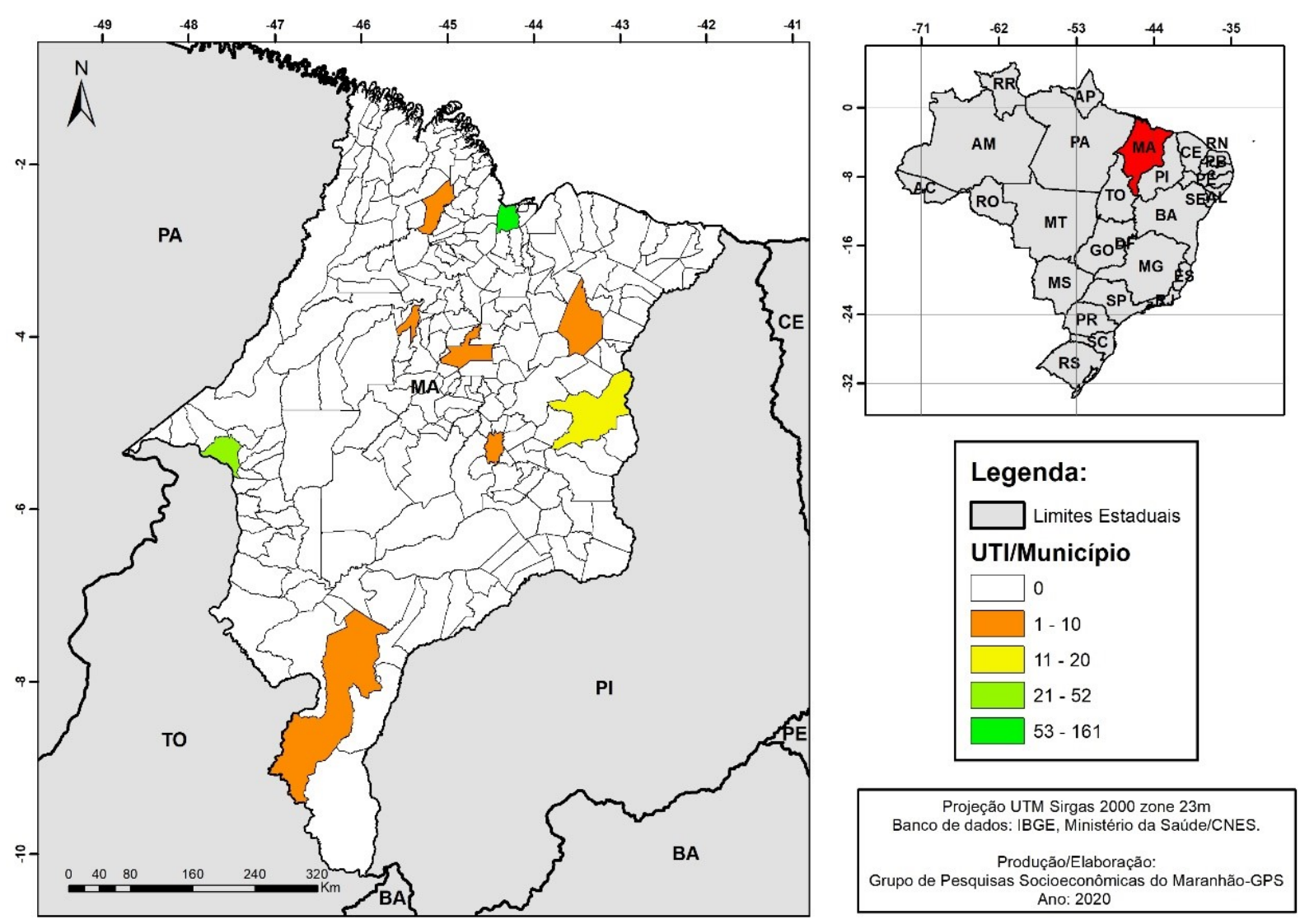

Figura 2 - Mapa da distribuição espacial de Unidades de Terapia Intensiva (UTIs) no Maranhão. Fonte: Dados Datasus (2020).

Org.: Os autores (2020). 
Das 293 unidades de terapia intensiva existentes no Maranhão, todas estão concentradas em apenas nove municípios. O vazio na distribuição da estrutura de saúde torna os municípios menores dependentes dos maiores, intensifica a mobilidade populacional e a debilidade no atendimento.

De modo semelhante, a distribuição espacial de leitos hospitalares (Figura 3) concentra-se em apenas 17 municípios. Desse total, duas cidades - São Luís e Imperatriz - concentram 74\% (376) de todos os leitos privados do estado. A parte sul do Maranhão é a região mais deficitária, com apenas três municípios (Imperatriz, Estreito e Balsas) apresentando 17\% de todos os leitos do estado.

Apenas 50 dos 287 municípios maranhenses contam com leitos hospitalares públicos. Destes, apenas 11 municípios têm mais de 10 leitos desse tipo. Assim como ocorre com o total de leitos, no caso dos leitos públicos também há concentração. Apenas duas cidades, São Luís e Imperatriz, concentram 64\% (495) de todos leitos públicos do Maranhão. Os dados apresentados reforçam a centralidade que essas duas cidades apresentam na dinâmica regional em relação aos serviços de saúde.

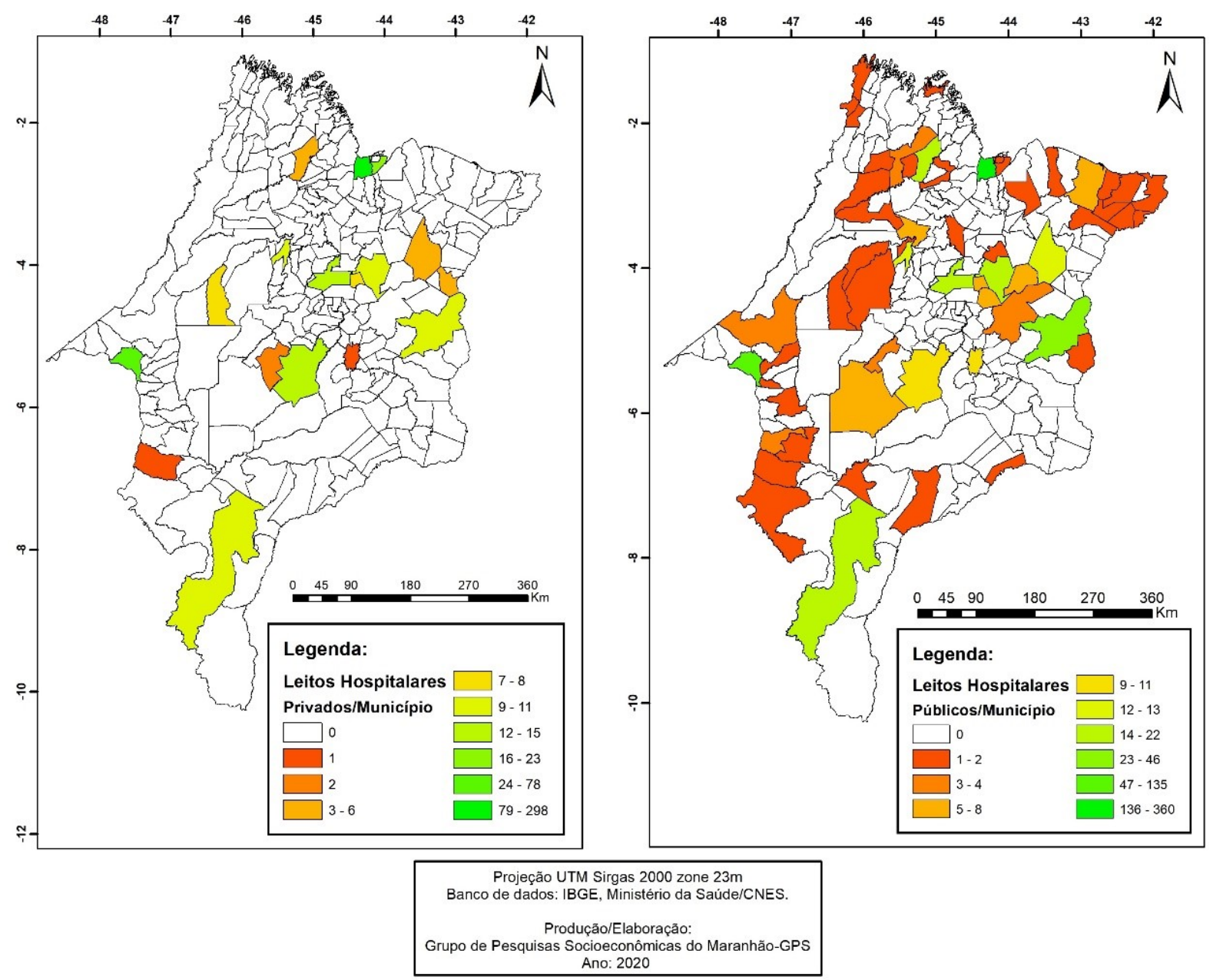

Figura 3 - Mapas da distribuição espacial de leitos hospitalares no Maranhão.

Fonte: Dados do Datasus (2020)

Org.: Os autores (2020). 
A alta demanda por respiradores/ventiladores mecânicos impulsionou a adoção de medidas que resultaram no aumento no quantitativo e na distribuição espacial desse equipamento médicohospitalar entre os municípios maranhenses (Figura 4). Em janeiro de 2020, havia, segundo dados do Datasus (2020), 1.061 respiradores/ventiladores mecânicos no estado; destes, aproximadamente 64\% encontravam-se na capital São Luís.

A adoção de medidas mais eficazes, por parte do governo do Estado, proporcionou aumento no número de respiradores/ventiladores mecânicos: 7\% em março; 4\% em abril; 7,5\% em maio; e 4\% em junho, em relação aos meses anteriores. Ao final de 100 dias de pandemia, haviam sido inseridos 269 novos aparelhos no sistema de saúde do estado. Com isso, as taxas de ocupação dos equipamentos não atingiram a totalidade, resultando em $93 \%$ da capacidade de ocupação em março; 94,5\% em abril; 94\% em maio e junho.

Entretanto, o aumento no quantitativo de respiradores/ventiladores e sua maior distribuição entre os municípios do Maranhão não reflete maior equidade no percentual de oferta dos equipamentos. Apenas 69 dos 181 municípios têm pelo menos 1 aparelho, e destes, 54 municípios têm menos de 10 respiradores. Somente São Luís concentra 50\% (674) de todos os respiradores do estado, seguida de Imperatriz, com 11\% destes.
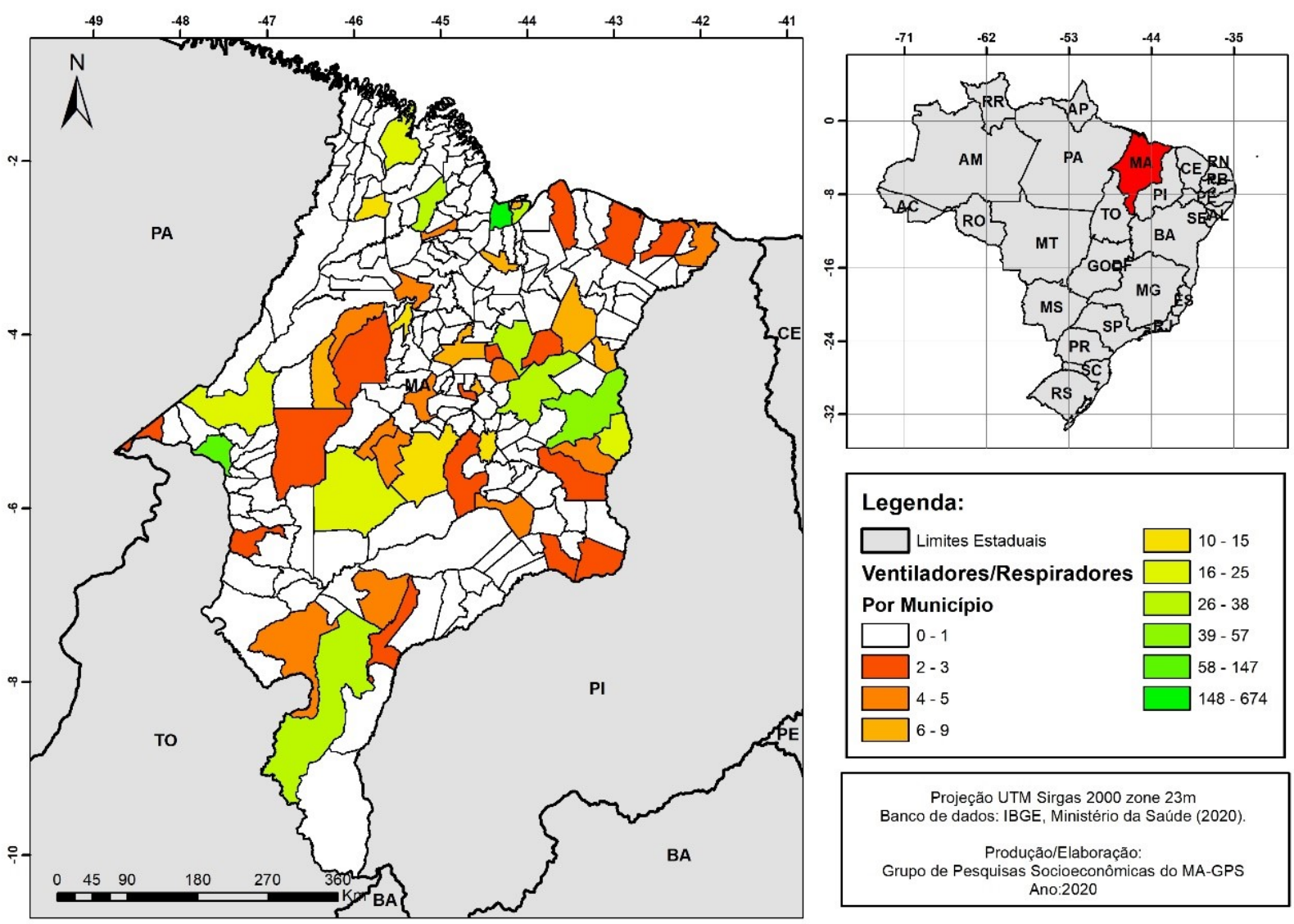

Figura 4 - Mapa da distribuição espacial de respiradores/ventiladores no Maranhão.

Fonte: Dados do Datasus (2020).

Org.: Os autores (2020). 
Na dinâmica regional, estes municípios apresentam relevância não apenas pelos fluxos econômicos no estado, mas por concentrarem a principal base de oferta de saúde - em especial, praticamente toda a oferta estadual - o que resulta em centralidades micro e mesorreginais atraindo enorme contingente de pacientes em busca de diagnóstico e tratamento que proporciona, em aspectos próprios, na dinâmica da difusão do Sars-Cov-2 no Maranhão.

\section{ENFRENTAMENTO DE COVID-19 EM 100 DIAS NO MARANHÃO}

O monitoramento da propagação da covid-19 no Maranhão iniciou-se oficialmente em 28 de fevereiro, a partir de dois casos suspeitos. O primeiro caso detectado data de 20 de março, na cidade de São Luís, no interior do estado o primeiro caso data de 27 de março na cidade de Imperatriz. O primeiro óbito estadual foi registrado no dia 29 do mesmo mês. Até o dia 31 de março, já havia 52 casos confirmados e 1 óbito (Figura 5). Em Imperatriz, o primeiro caso data de 27 de março. Nos casos iniciais, o fluxo aeroviário foi fundamental para a propagação, uma vez que o primeiro paciente detectado havia retornado de viagem ao estado de São Paulo (MARANHÃO, 2020b).

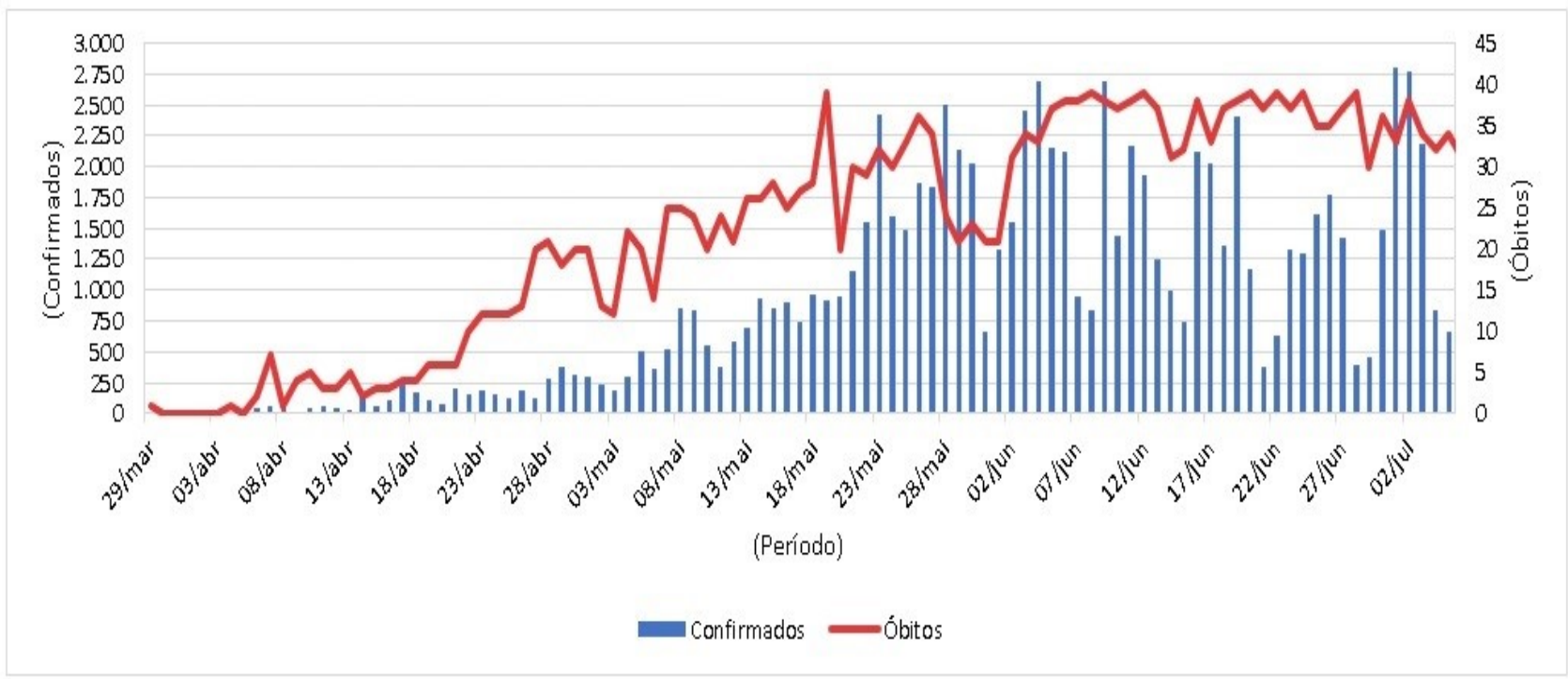

Figura 5 - Evolução de casos confirmados e óbitos por covid-19 no Maranhão. Fonte: Dados da SES/MA (MARANHÃO, 2020b).

Org.: Os autores (2020).

O Maranhão entrou em quarentena no dia 17 de março. Voos foram cancelados e as fronteiras terrestres foram fechadas, aulas presenciais nas instituições de ensino foram suspensas e o governo do Estado emitiu decreto estabelecendo normas sanitárias de funcionamento, especialmente para os serviços essenciais (MARANHÃO, 2020a). Ao final de 100 dias, foram confirmados 90.251 casos de covid-19 e 2.250 óbitos, média de 1 óbito para cada 40 pessoas infectadas, ou média de 22,5 óbitos por dia. O pico da doença (tanto contágio quanto óbitos) deu-se no mês de junho (MARANHÃO, 2020b). 
Quanto ao perfil de contágio (Figura 6) dos meses de abril, maio e junho, o grupo etário com maior nível de contágio está compreendido na faixa etária dos 30 a 39 anos (16.446 casos) o que pode sugerir estreita relação com a População Economicamente Ativa no estado. Em seguida, vieram as faixas dos 40 a 49 anos (13.282 casos) e 20 a 29 anos (11.448 casos). Já em relação ao número de óbitos, aqueles acima de 70 anos de idade constituem mais de $53 \%$ dos casos. Crianças e jovens de 0 a 29 apresentaram a menor taxa de mortalidade, com 50 (2\%) óbitos no total.

Quanto ao sexo, a maioria dos infectados são homens, que também representam maior percentual de óbitos (62\%). Embora não seja o objetivo deste trabalho se aprofundar nessas questões, acredita-se na hipótese de que a precarização do trabalho e a vulnerabilidade do trabalhador sejam relevantes para que este assuma comportamentos de risco, não praticando distanciamento e isolamento social. Isso pode contribuir para que o contágio tenha sido maior entre os homens.

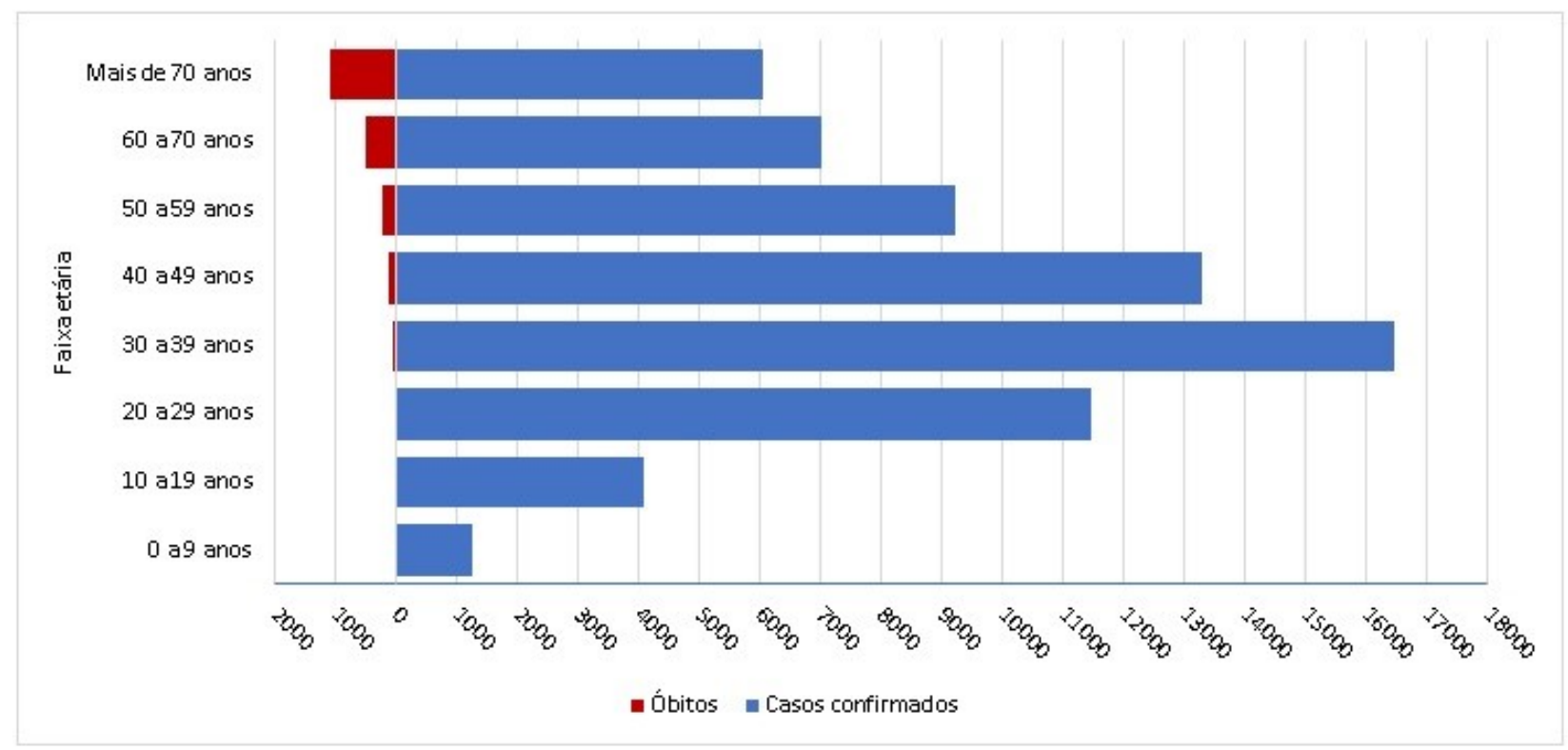

Figura 6 - Evolução de casos confirmados e óbitos por covid-19 no Maranhão. Fonte: Dados da SES/MA (MARANHÃO, 2020b).

Org.: Os autores (2020).

Dentre as comorbidades associadas mais frequentes estão hipertensão, diabetes e sobrepeso. O Maranhão iniciou o enfretamento da pandemia com 132 leitos destinados exclusivamente à internação de paciências com covid-19. A expansão desse número, nos 100 primeiros dias de pandemia, chegou a 449 leitos no último dia do período em análise, totalizando $70 \%$ de aumento (Figura 7). Esse aumento possibilitou que o sistema não entrasse em colapso; o maior percentual de ocupação foi de 93,03\%, no mês de maio (DATASUS, 2020; MARANHÃO, 2020b). 


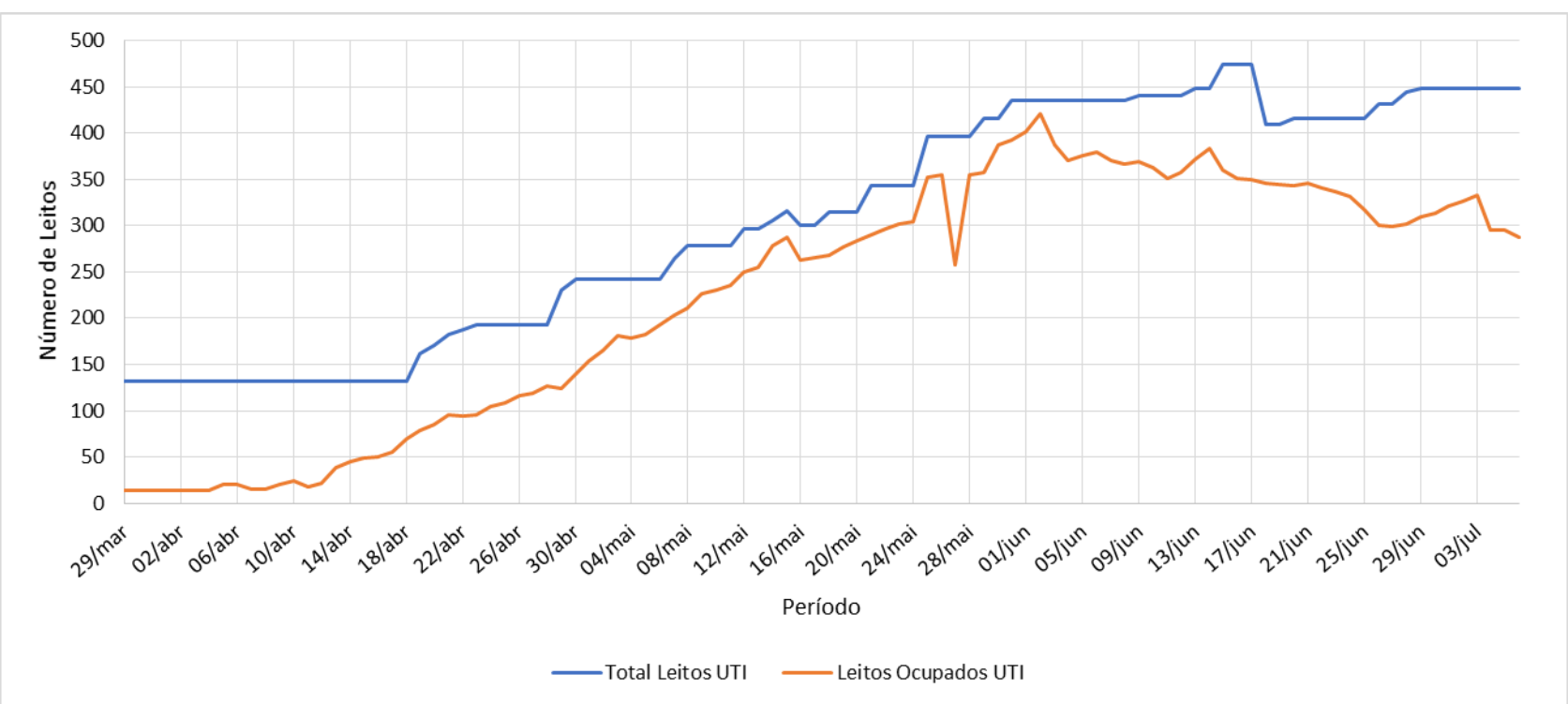

Figura 7 - Evolução de incremento/ocupação de UTIs para atendimento de covid-19 no Maranhão.

Fonte: Dados da SES/MA (MARANHÃO, 2020b).

Org.: Os autores (2020).

Com o incremento de hospitais de campanha (Figura 8), também se ampliou temporariamente o número de leitos hospitalares clínicos na rede de atendimento destinada ao covid19 no estado. Em 29 de março, havia 120 leitos clínicos destinados à pandemia, com taxa de ocupação de apenas 8,33\%. Esse número chegou a 1.151 leitos no dia 6 de julho (último dia do período analisado), o que resultou em aumento de $950 \%$. O maior nível de ocupação foi no dia 15 de maio, $\operatorname{com} 82,22 \%$.

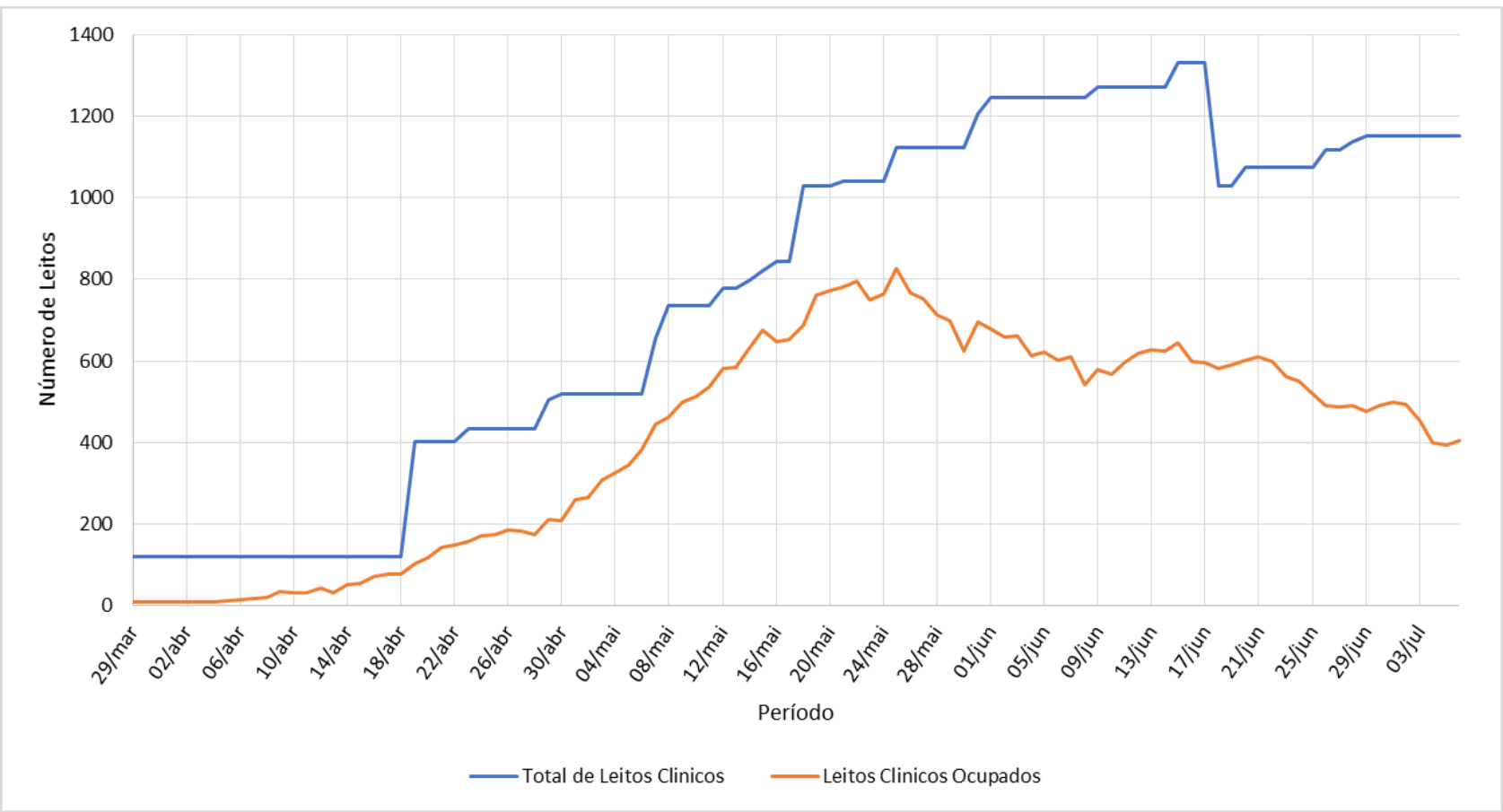

Figura 8 - Evolução de incremento/ocupação de leitos clínicos para atendimento de covid-19 no Maranhão. Fonte: Dados da SES/MA (MARANHÃO, 2020b).

Org.: Os autores (2020). 
Mesmo com incremento significativo de equipamentos médico-hospitalares para o enfrentamento da pandemia, estes foram concentrados nos principais centros urbanos estaduais, acentuando as centralidades no âmbito da saúde e as disparidades regionais preexistentes. Isso fez com que o número de casos registrados fosse maior nesses centros que receberam pessoas de outras localidades.

Na figura 9, é possível observar no mapa os cinco principais centros urbanos do Maranhão com a maior concentração de casos confirmados. Esses centros concentraram $83 \%$ dos hospitais de campanha, $64 \%$ do total de respiradores/ventiladores mecânicos, 79\% das UTIs do estado, além de $71 \%$ de todas as UTIs públicas e privadas existentes.

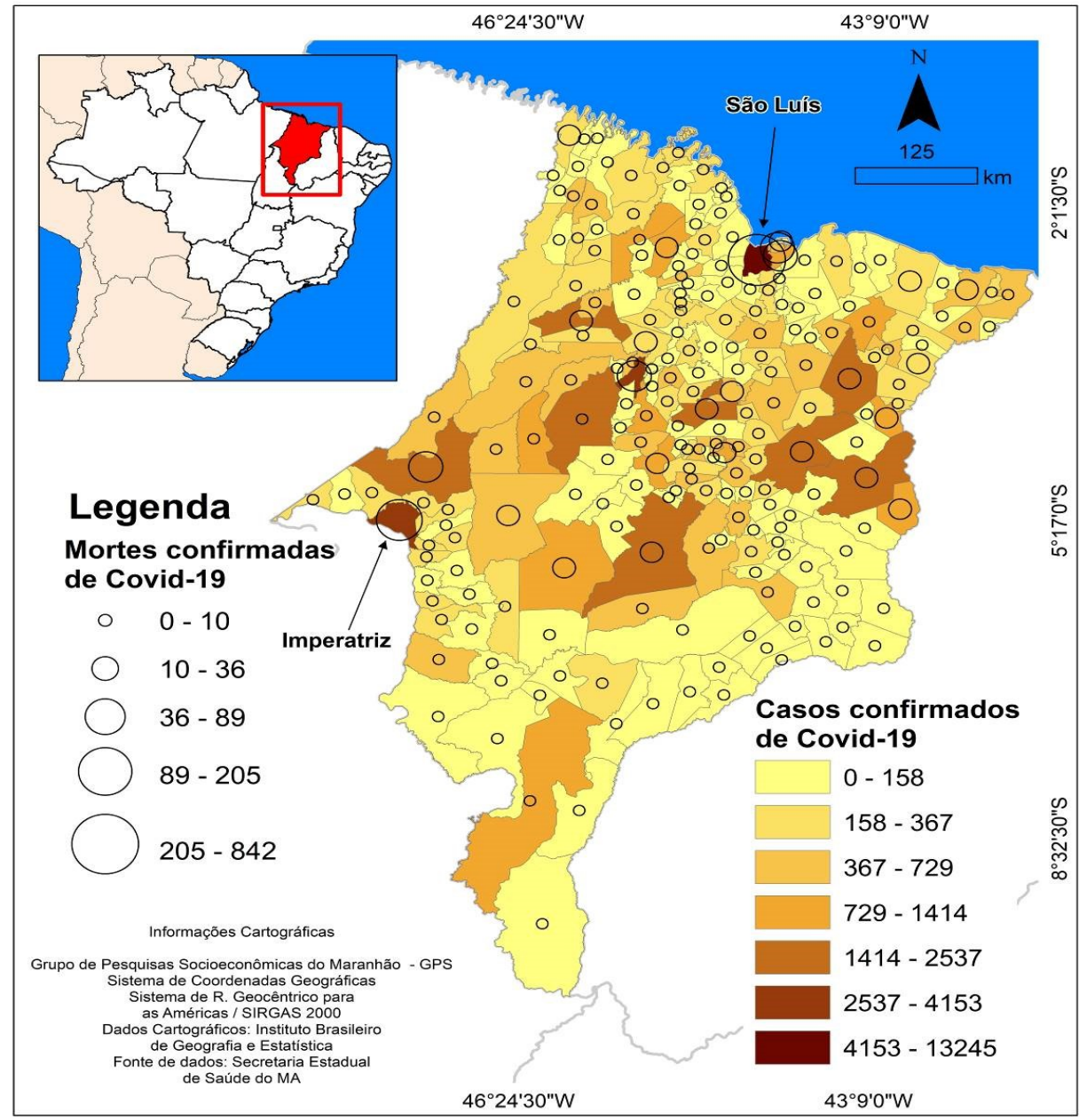

Figura 9 - Mapa da distribuição espacial de casos e mortes confirmadas por covid-19 no Maranhão. Fonte: Dados da SES/MA (MARANHÃO, 2020b).

Org.: Os autores (2020).

A atração de pessoas para os centros que concentram serviços de saúde faz com que mesmo os centros com maior capacidade de oferta tenham altos índices de contágio e mortalidade. Isso porque essa dinâmica faz com que eles passem a responder por demandas regionais, além das internas. 
Por exemplo: a cidade de São Luís, que registrou 842 óbitos, com taxa de letalidade de 6,36\%; e a de Imperatriz, com 205 óbitos e taxa de letalidade de 4,94\%, os dois ${ }^{4}$ maiores índices estaduais.

Essa dinâmica, característica da rede urbana do estado, subdimensiona a situação real, já que, segundo protocolos da secretaria de saúde, os casos detectados nos centros maiores passam a compor a base de dados do município de origem do paciente, e não a do município onde foi detectada e tratada a doença. Assim, representa-se apenas pequeno recorte da realidade da dispersão viral no estado.

\section{ASPECTOS DA DIFUSÃO DE COVID-19 NA REGIÃO GEOGRÁFICA IMEDIATA DE IMPERATRIZ, MARANHÃO}

É fundamental entender a dinâmica territorial histórica da Região Geográfica Imediata de Imperatriz e dos 17 municípios que a integram. Fundada em 16 de julho de 1852, Imperatriz teve parte expressiva de sua base territorial desmembrada a partir do início do século XX (Figura 10). Boa parte desse desmembramento deu-se a partir da criação e emancipação de novos municípios.

Entre 1920 e 1955, os municípios de Porto Franco, Amarante do Maranhão, Estreito e Montes Altos foram emancipados e elevados à categoria de cidade. Em seguida, em 1961, João Lisboa e Sítio Novo desmembraram-se de Imperatriz; e, em 1981, em meio ao processo de expansão da área de influência do Grande Projeto Carajás, Açailândia também se tornou uma cidade autônoma.

O maior desmembramento territorial ocorreu na década de 1990, começando em 1994, quando os municípios de Cidelândia, Davinópolis, Lajeado Novo, São Francisco do Brejão, São Pedro dos Crentes, Vila Nova dos Martírios, Campestre do Maranhão, São João do Paraíso e Feira Nova do Maranhão desvincularam-se da unidade político-territorial de Imperatriz. Dois anos depois, em 1996, foi a vez dos municípios de Buritirana, Itinga do Maranhão, Ribamar Fiquene e Senador La Rocque.

Parte expressiva dos municípios originários dessas fragmentações compõe atualmente a região de influência de Imperatriz e sua rede urbana. Essa composição geográfica decorre não apenas do estabelecimento de fluxos de bens, capitais, mercadorias e pessoas em torno da centralidade de Imperatriz, mas também de relações históricas constituídas regionalmente.

Parte expressiva dos processos históricos de desmembramento territorial não foram acompanhados por emancipação administrativa no que compete a atenção a saúde, seja por ingerência política ou por limitação orçamentária. As fragmentações municipais possibilitaram a criação de

\footnotetext{
${ }^{4}$ É importante destacar que há cidades com taxa de letalidade bem superior às duas em questão, tais como: Alcântara, com 30 casos e 5 mortes (letalidade de 16,67\%); Boa Vista do Gurupi, com 12 casos e 2 mortes (letalidade de 16,67\%); Cândido Mendes, com 24 casos e 4 mortes (letalidade de 16,67\%); e Cajapió, com 5 casos e 2 mortes (letalidade de 40\%). Entretanto, todos esses integram o conjunto de 184 municípios cuja centralidade e atuação não extrapolam os limites de sua área territorial (IBGE, 2008). A título de exemplificação, nenhum deles tem UTI, leitos hospitalares ou mesmo ventiladores/respiradores em sua rede de saúde, o que obriga seus moradores a se deslocarem para centros maiores.
} 
novos municípios do que se tem hoje como a área da Região Geográfica Imediata de Imperatriz, mas elas não foram acompanhadas de ampliação do atendimento médico-hospitalar, principalmente aquele de média e alta complexidade.

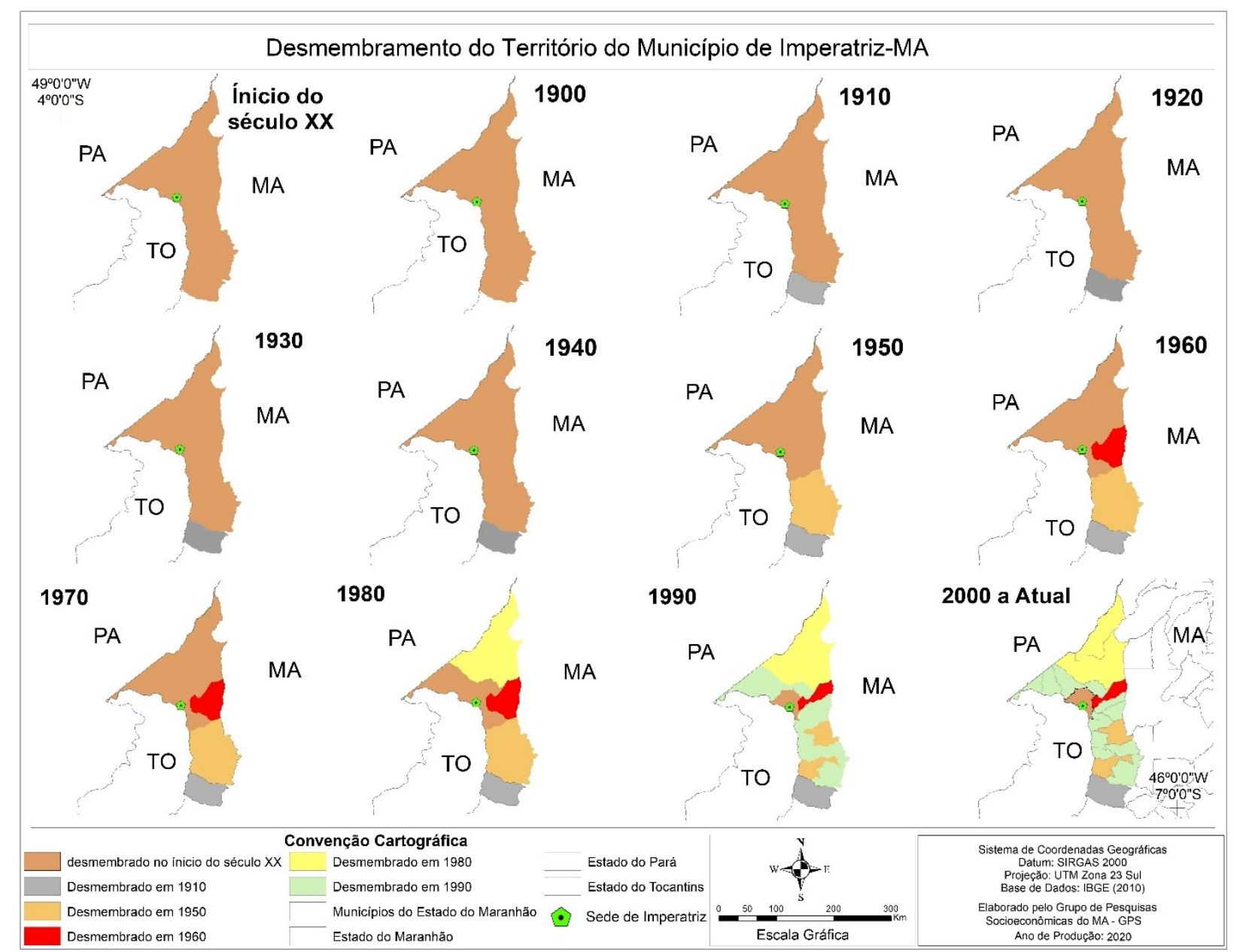

Figura 10 - Desmembramento do território de Imperatriz.

Fonte: Dados do IBGE (2010).

Org.: Os autores (2020).

Este contexto permitiu que os fluxos de pessoas em busca de serviços (bancários, comércio, educação e saúde) em direção a Imperatriz permanecesse ao longo dos anos - constituindo assim uma rede urbana - na medida em que a cidade aumentava sua capacidade de oferta-los.

Na saúde, os limites territoriais de municípios que anteriormente faziam parte de um todo, deixam de fazer tanto sentido, sobretudo em uma pandemia, intensificando a polarização de Imperatriz sobre os demais. Ou nas palavras de Rochefort, (1998, p. 15) "todo serviço atende tanto às necessidades dos habitantes da aglomeração onde se localiza quanto às das pessoas que habitam na zona de influência desta".

Nessa perspectiva, considerando a escassa oferta de serviços públicos de saúde no Maranhão e a sua concentração em poucos centros urbanos, como Imperatriz, é salutar considerar que a cidade 
atenda, até certo ponto, tanto sua demanda interna quanto a de centros vizinhos, localizados sob sua influência imediata e intermediária, principalmente considerando a distribuição de leitos, UTIs e respiradores (Tabela 1) nos municípios que compõem sua região geográfica imediata.

Tabela 1: Síntese da oferta de serviços de saúde nos principais centros urbanos no Maranhão em 100 dias de pandemia de covid-19.

\begin{tabular}{l|c|c|c}
\hline \multicolumn{1}{c|}{ Município } & $\begin{array}{c}\text { Leitos públicos e } \\
\text { privados }\end{array}$ & $\begin{array}{c}\text { UTIs públicas e } \\
\text { privadas }\end{array}$ & Respiradores \\
\hline Imperatriz & 213 & 52 & 147 \\
Amarante do Maranhão & - & - & 3 \\
Buritirana & - & - & - \\
Campestre & - & - & - \\
Cidelândia & - & - & - \\
Davinópolis & 1 & - & - \\
Estreito & 3 & - & - \\
Governador Edison Lobão & - & - & - \\
João Lisboa & 2 & - & - \\
Lajeado Novo & - & - & - \\
Montes Altos & 2 & - & - \\
Porto Franco & 4 & - & 2 \\
Ribamar Fiquene & - & - & - \\
São João do Paraíso & 1 & - & - \\
São Pedro da Água Branca & - & - & 3 \\
Senador La Rocque & - & - & - \\
Vila Nova dos Martírios & - & - & - \\
\hline
\end{tabular}

Fonte: Dados do Datasus (2020) e da Secretaria de Estado da Saúde do Maranhão (2020b). Org.: Os autores (2020).

Esses e outros gargalos motivaram a criação de pactos intermunicipais, tendo em vista a regionalização da saúde no estado, instituída pela Comissão Intergestores Bipartite (CIB/MA), por meio da Resolução no 44/2011, de 16 de junho de 2011. Devido a essa dinâmica de regionalização, muitos pacientes de municípios vizinhos são enviados a Imperatriz para tratamento de saúde, sobretudo de alta e média complexidade.

O aumento desses fluxos de pessoas amplia as possibilidades de contágio por coronavírus, além de concentrar o número de casos nos centros urbanos de maior capacidade de polarização, subdimensionando a origem geográfica do paciente com covid-19. Na figura 11, é possível observar que o número de casos confirmados em Imperatriz é muito superior aos números dos demais municípios de sua região imediata. Nos 100 primeiros dias de pandemia, a cidade registrou 4.153 casos confirmados, em comparação aos 3.307 casos registrados por todos os outros municípios. 


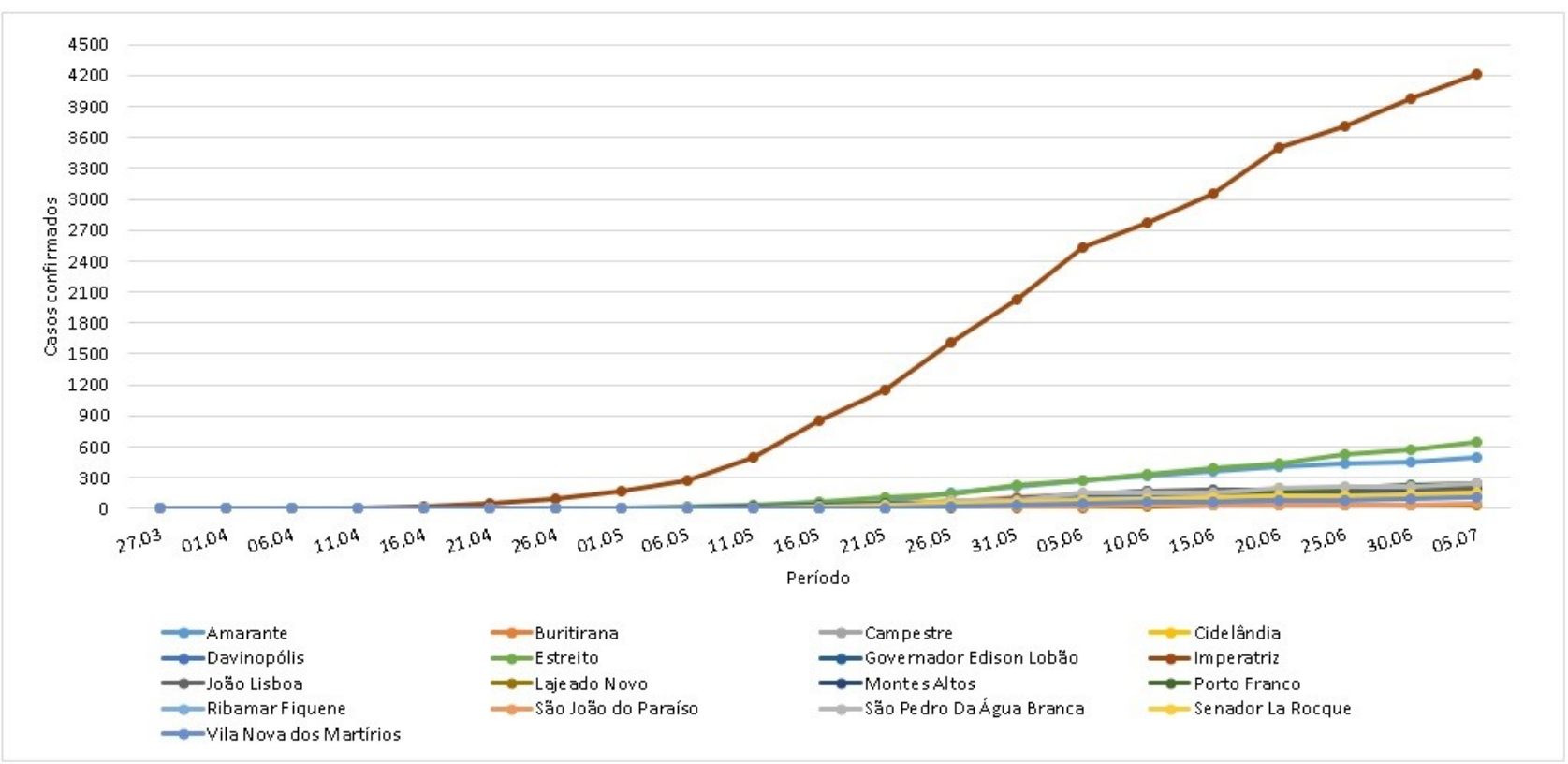

Figura 11 - Casos confirmados de covid-19 em municípios da Região Geográfica Imediata de Imperatriz. Fonte: Dados do Datasus (2020) e da Secretaria de Estado da Saúde do Maranhão (2020b).

Org.: Os autores (2020).

A confirmação do número de óbitos (Figura 12) por complicações causadas por covid-19 é feita no atendimento público, em hospitais de referência e/ou de campanha, e na rede privada. Nessas estatísticas também se reproduz a mesma lógica de concentração geográfica, isto é, o número de óbitos registrados em torno da cidade de Imperatriz (205) ultrapassa, o somatório de óbitos por covid19 em todos os outros municípios (59). Nesse caso, dadas as limitações da oferta de equipamentos médico-hospitalares no estado, é de se considerar que todos esses pacientes tenham sido tratados em Imperatriz, exceto aqueles removidos pelo poder público ou de modo particular.

A movimentação de pessoas em direção ao centro de referência provoca clara subnotificação dos casos quanto à procedência geográfica do paciente, informação fundamental para compreender a dinâmica do contágio e criar mecanismos de controle. Embora o protocolo de monitoramento da saúde estadual determine que as informações relativas a casos confirmados e/ou óbitos devem retornar ao município de origem do paciente, os casos em que isso ocorre representam apenas uma pequena parcela da totalidade de registros. 


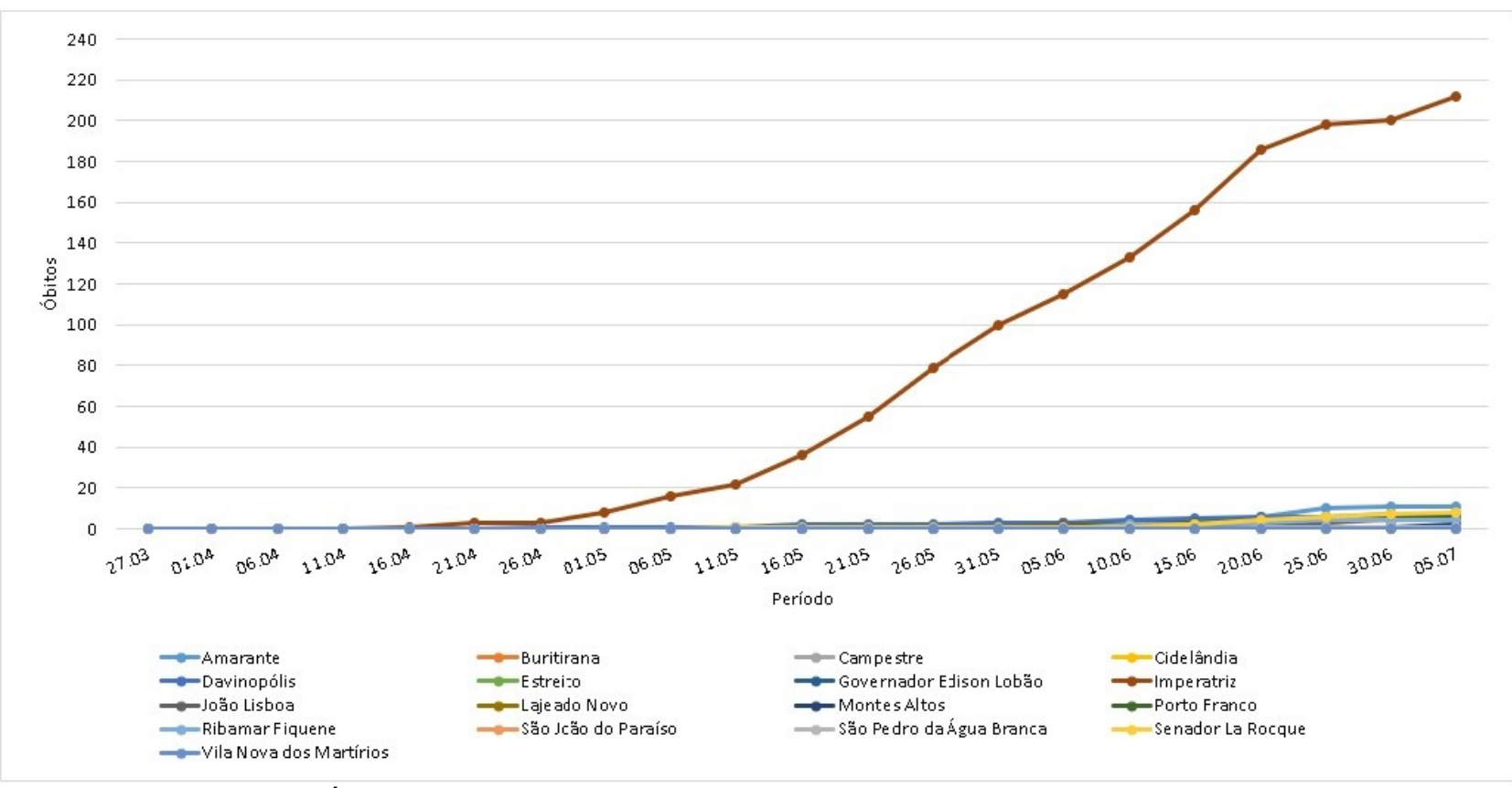

Figura 12 - Óbitos por covid-19 em municípios da Região Geográfica Imediata de Imperatriz. Fonte: Dados do Datasus (2020) e da Secretaria de Estado da Saúde do Maranhão (2020b).

Org.: Os autores (2020).

Isso acontece porque apesar de muitas pessoas residirem, oficialmente, nos municípios que integram a Região Geográfica Imediata, as continuidades de família, trabalho, educação e busca por serviços contribuem para que muitos indivíduos indiquem a cidade de Imperatriz como domicílio.

Pode-se constatar esse fato observando-se as estatísticas de dados cadastrais do "cartão do SUS”. Quando considerado o quantitativo de pessoas com o Cartão Nacional de Saúde (BRASIL, 2020a) que indicam Imperatriz como local de residência, são encontrados 436.687 registros ativos, contudo a população da cidade é de apenas 258.682 habitantes (IBGE, 2020). Desta forma, 59,46\% das pessoas atendidas nos serviços de saúde da cidade não são seus residentes, o que representa um gargalo na compreensão da dinâmica geográfica do trânsito de pessoas pela rede urbana na pandemia.

A partir de dados do Datasus e do Cartão Nacional de Saúde, também se observou a procedência geográfica (Figura 13) de pessoas com covid-19 atendidas na rede hospitalar, pública e privada, de Imperatriz. No mapa, aparecem 48 municípios, indicando que a pandemia fez com que a influência da cidade extrapolasse a abrangência de sua região imediata. Isso amplia a compreensão acerca dos fluxos de busca por atendimento e destaca a capacidade de polarização da cidade em relação a outros centros urbanos, no âmbito da saúde, nos 100 primeiros dias de pandemia. 


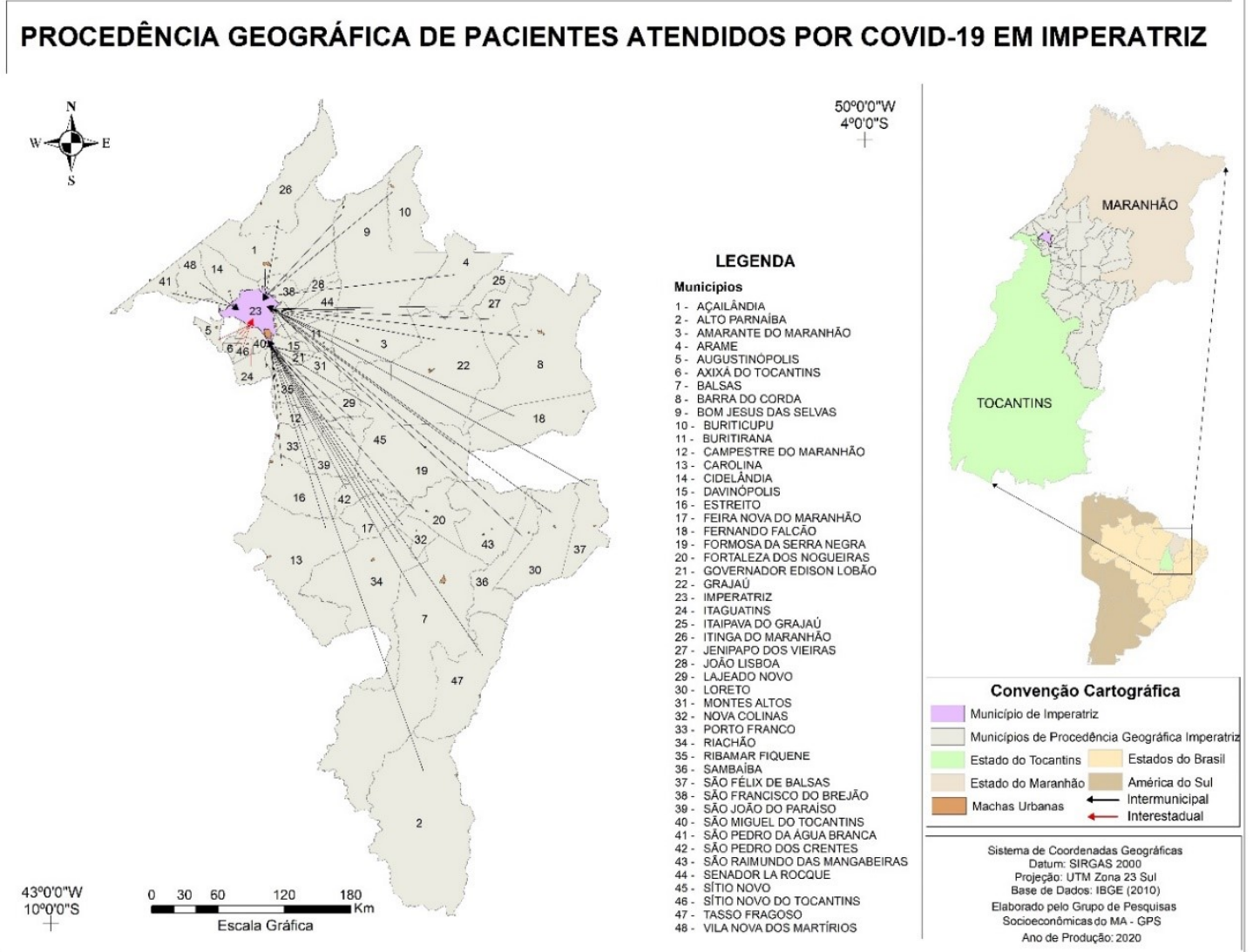

Figura 13 - Procedência geográfica de pacientes atendidos por covid-19 em Imperatriz. Fonte: Dados do Datasus (2020). Org.: Os autores (2020).

O mapa construído a partir dos dados da procedência geográfica de pacientes atendidos com covid-19 em Imperatriz apresenta a amplitude da capacidade de polarização do município e a extensa área de pendularidade de pacientes em busca de serviços de saúde na pandemia. Em especial, de municípios próximos, que fazem parte da Região Geográfica, como João Lisboa, Davinópolis e Senador La Rocque, cujas distâncias até Imperatriz são de 12 km, 15 km e 26 km, respectivamente ou de municípios mais distantes que fogem a essa regionalização, como Alto Parnaíba, São Félix de Balsas e Tasso Fragoso, distantes 623 km, 500 km e 520 km, respectivamente. Além destas, também partem fluxos de cidades do estado do Tocantins.

Fora o subdimensionamento de informações, acerca da procedência geográfica do paciente atendido na cidade, essa pendularidade também cria uma ampla área de difusão viral. Contando apenas a população dos municípios maranhenses compreendidos nessa região de influência, há um contingente populacional de mais de 1.307.495 habitantes, possíveis vetores transitando nos fluxos.

\section{CONSIDERAÇÕES FINAIS}

Há muito o que se analisar a partir do fenômeno viral do novo coronavírus no Maranhão, e estas considerações são apenas preliminares diante da necessidade de se compreender mais 
amplamente a dinâmica da pandemia em todo o estado, considerando a sistematização mais clara e uniforme dos dados. Apesar disso, este estudo preliminar levanta importantes reflexões.

A concentração de serviços de saúde (em especial, UTIs, leitos hospitalares e respiradores) nos principais centros urbanos do Maranhão, não só configura relevante característica de uma região periférica, como também gera uma expressiva mobilidade de pessoas em um amplo contexto regional do estado, o que, por si só, já enfraquece a manutenção de medidas de isolamento social.

Há um inegável componente histórico na formação territorial de Imperatriz e de parte dos municípios que integram sua Região Geográfica Imediata que tem a ver com a construção, também histórica, de uma pendularidade de pessoas, acentuada no âmbito da saúde pela concentração da oferta de serviços nessa área.

No tocante a essa característica, é fundamental ressaltar que as disparidades entre a oferta de serviços e a demanda por atendimento na pandemia fizeram com que a influência da cidade ultrapassasse sua região geográfica e alcançasse uma área mais ampla, abrangendo municípios de quase toda a porção sul do estado e até municípios do Tocantins, o que contribui para a manutenção de uma ampla área de contágio na rede urbana municipal.

A origem dos pacientes atendidos nem sempre é identificada corretamente, uma vez que os dados do Cartão Nacional de Saúde, que alimentam as estatísticas oficiais, costumam apresentar incongruências no cadastro de domicílios, resultando em imprecisões e distorções quanto à geografia do contágio. Tais questões, somadas a pendularidade de pessoas em busca de atendimento, representam um dos principais aspectos da difusão viral de covid-19 na Região Geográfica Imediata de Imperatriz.

\section{REFERÊNCIAS}

ARAÚJO, J. A. V. A região de influência de Imperatriz - MA: estudo da polarização de uma capital regional, destacando a regionalização dos serviços públicos de saúde. 2016. 216 f. Dissertação (Mestrado em Desenvolvimento Urbano) - Universidade Federal de Pernambuco, Recife, 2016.

BARRETO, M. L.; BARROS, A. J. D.; CARVALHO, M. S.; CODEÇO, C. T.; HALLAL, P. R. C.; MEDRONHO, R. A.; STRUCHINER, C. J.; VICTORA, C. G.; WERNECK, G. L. O que é urgente e necessário para subsidiar as políticas de enfrentamento da pandemia de COVID-19 no Brasil? Revista Brasileira de Epidemiologia, Rio de Janeiro, v. 23, p. 1-4, 2020.

BESSA, K.; LUZ, R. A. A pandemia de Covid-19 e as particularidades regionais da sua difusão no segmento de rede urbana no estado do Tocantins, Brasil. Ateliê Geográfico, Goiânia, v. 14, n. 2, p. 06-28, 2020.

BRASIL - MINISTÉRIO DA SAÚDE. Cartão Nacional do SUS. 2020a. Disponível em: https://www.saude.gov.br/acoes-e-programas/cartao-nacional-de-saude. Acesso em: 19 jul. 2020. 
BRASIL - MINISTÉRIO DA SAÚDE. Painel coronavírus Brasil. 2020b. Disponível em: https://covid.saude.gov.br/. Acesso em: 14 jun. 2020.

BRASIL - MINISTÉRIO DA SAÚDE. Portal coronavírus covid-19. 2020c. Disponível em: https://coronavirus.saude.gov.br/sobre-a-doenca\#transmissao. Acesso em: 22 ago. 2020.

CORRÊA, R. L. A rede urbana. 3. ed. São Paulo: Ática, 1997. 96p.

CORRÊA, R. L. Estudos sobre a rede urbana. 1. ed. São Paulo: Bertrand Brasil, 2006. 332p.

DATASUS - DEPARTAMENTO DE INFORMÁTICA DO SUS. Ministério da Saúde. Sistema de informações à saúde. $2020 . \quad$ Disponível em: http://www2.datasus.gov.br/DATASUS/index.php?area=02. Acesso em: 10 jun. 2020.

DROSTEN C.; GÜNTHER, S.; PREISER, W.; WERF, S. V. D.; BRODT, H. R.; BECKER, S.; RABENAU, H.; PANNING, M.; KOLESNIKOVA, L.; FOUCHIER, R. A. M.; BERGER, A.; BURGUIÈRE, A. M.; CINATL, J.; EICKMANN, M.; ESCRIOU, N.; GRYWNA, KLAUS, KRAMME, S.; MANUGUERRA, J. C.; MÜLLER, S.; RICKERTS, V.; STÜRMER, M.; VIETH, S.; KLENK, H. D.; OSTERHAUS, A. D. M. E.; SCHMITZ, H.; DOERR, H. W. Identification of a novel coronavirus in patients with severe acute respiratory syndrome. The New England Journal of Medicine, v. 348, n. 20, p. 1967-1976, 2003.

FARIAS, H. S. O avanço da Covid-19 e o isolamento social como estratégia para redução da vulnerabilidade. Espaço e Economia, ano 9, n. 17, abr. 2020.

HAESBAERT, R. Reflexões geográficas em tempos de pandemia. Espaço e Economia, ano 9, n. 18, abr. 2020.

IBGE. Divisão Regional do Brasil 2017. 2018. Disponível em: https://www.ibge.gov.br/geociencias/organizacao-do-territorio/divisao-regional/15778-divisoesregionais-do-brasil.html?=\&t=acesso-ao-produto. Acesso em: 20 set. 2020.

IBGE. Regiões de influência das cidades 2007. 2008. Disponível em: https://biblioteca.ibge.gov.br/visualizacao/livros/liv40677.pdf. Acesso em: 21 out. 2020.

JOHNS HOPKINS UNIVERSITY. COVID-19 Dashboard by the Center for Systems Science and Engineering (CSSE) at Johns Hopkins University (JHU). 2020. Disponível em: https://coronavirus.jhu.edu/map.html. Acesso em: $17 \mathrm{dez} .2020$.

KSIAZEK, T. G.; ERDMAN, D.; GOLDSMITH, C. S.; ZAKI, S. R.; PERET, T.; EMERY, S.; TONG, S.; URBANI, C.; COMER, J. A.; LIM, W.; ROLLIN, P. E.; DOWELL, S. F.; LING, A. E.; HUMPHREY, C. D.; SHIEH, W. J.; GUARNER, J.; PADDOCK, C. D.; ROTA, P.; FIELDS, B.; DERISI, J.; YANG, J. Y.; COX, N.; HUGHES, J. M.; LEDUC, J. W.; BELLINI, W. J.; ANDERSON, L. J. A novel coronavirus associated with severe acute respiratory syndrome. The New England Journal of Medicine, v. 348, n. 20, p. 1953-1966, 2003.

LI, Q.; GUAN, X.; WU, P.; WANG, X.; ZHOU, L.; TONG, Y.; REN, R.; LEUNG, K. S. M.; LAU, E. H. Y.; WONG, J. Y.; XING.; X.; XIANG, N.; WU, Y.; LI, C.; CHEN, Q.; LI, D.; LIU, T.; ZHAO, J.; LIU, M.; TU, W.; CHEN, C.; JIN, L.; YANG, R.; WANG, Q.; ZHOU, S.; WANG, R.; LIU, H.; LUO, Y.; LIU, Y.; SHAO, G.; LI, H.; TAO, Z.; YANG, Y.; DENG, Z.; LIU, B.; MA, Z.; ZHANG, Y.; SHI, G.; LAM, T. T. Y.; WU, J. T.; GAO, G. F.; COWLING, B. J.; YANG, B.; LEUNG, G. M.; 
FENG, Z. Early transmission dynamics in Wuhan, China, of novel coronavirus-infected pneumonia. The New England Journal of Medicine, v. 382, n. 13, p. 1199-1207, 2020.

MARANHÃO. Secretaria de Comunicação Social e Assuntos Políticos. Coronavírus Maranhão. 2020a. Disponível em: https://www.corona.ma.gov.br/atos-normativos. Acesso em: 20 ago. 2020.

MARANHÃO. Secretaria de Estado da Saúde. Coronavírus: covid-19 no Maranhão. 2020b. Disponível em: https://painel-covid19.saude.ma.gov.br/. Acesso em: 15 jul. 2020.

MARANHÃO. Secretaria de Estado da Saúde. Resolução CIB/MA no 44/2011, de 16 de junho de 2011. Disponível em: https://www.mpma.mp.br/arquivos/COCOM/arquivos2011.pdf. Acesso em: 20 ago. 2020.

OSTERHAUS A. D. M. E.; FOUCHIER, R. A. M.; KUIKEN, T. The aetiology of SARS: Koch's postulates fulfilled. Philosophical Transactions of the Royal Society B: Biological Sciences, London, v. 359, n. 1447, p. 1081-1082, 2004.

PNUD - PROGRAMA DAS NAÇÕES UNIDADES PARA O DESENVOLVIMENTO; IPEA INSTITUTO DE PESQUISAS ECONÔMICAS APLICADA; FJP - FUNDAÇÃO JOÃO PINHEIRO. Atlas do Desenvolvimento Humano no Brasil. 2013. Disponível em: http://www.atlasbrasil.org.br/2013/pt/perfil_uf/maranhao. Acesso em: 17 ago. 2020.

ROCHEFORT, M. Redes e sistemas: ensinando sobre o urbano e a região. 1. ed. São Paulo: Hucitec, 1998. 174p.

SANTOS, M. A natureza do espaço: técnica e tempo, razão e emoção. 1. ed. São Paulo: Hucitec, 1996. 377p.

SPOSITO, M. E. B.; GUIMARÃES, R. B. Por que a circulação de pessoas tem peso na difusão da pandemia. In: UNIVERSIDADE ESTADUAL PAULISTA. Notícias Unesp. São Paulo: Unesp, 2020. Disponível em: https://www2.unesp.br/portal\#!/noticia/35626/por-que-a-circulacao-depessoas-tem-peso-na-difusao-da-pandemia. Acesso em: 23 jul. 2020.

VAN DER HOEK, L.; PYRC, K.; BERKHOUT, B. Human coronavirus NL63, a new respiratory virus. FEMS Microbiology Reviews, v. 30, n. 5, p. 760-773, 2006.

WHO - WORLD HEALTH ORGANIZATION. Novel coronavírus (2019-nCoV): situation report - 1. 2020. Disponível em: https://www.who.int/docs/default-source/coronaviruse/situationreports/20200121-sitrep-1-2019-ncov.pdf?sfvrsn=20a99c10_4. Acesso em: 13 jul. 2020.

Trabalho enviado em 29/10/2020

Trabalho aceito em 22/01/21 